\title{
NK Cell Activation
}

National Cancer Institute

\section{Source}

National Cancer Institute. NK Cell Activation. NCI Thesaurus. Code C19940.

NK Cell Activation involves interaction with virus-infected or transformed cells by diverse adhesion or co-stimulatory molecules and release of cytokines, chemokines, and lethal chemicals from granules. 